\title{
Monetary Policy Response on Exchange Rate Dynamics: The Case of Indonesia
}

\author{
Dr. Ferry Syarifuddin (Bank Indonesia, Indonesia)
}

\begin{abstract}
Bank Indonesia has been implementing Enhanced Inflation Targeting Framework (EITF) since few years ago. The main monetary instrument is short term policy interest rate. The policy interest rate, in this regard, may also have significant role in driving the exchange rate to its desired level. Setting appropriate the interest rate to drive the exchange rate is important to drive the actual inflation to its official target. In order to see the response of policy interest rate to exchange rate dynamics as well as the impact of exchange-rate dynamics to macroeconomic indicators, Structural Co-integrating Vector Auto Regression (SC-VAR) in an open economy model, is implemented. Its finding shows that exchange rate dynamic of USD/IDR has significantly positive relationship with domestic interest rate. The increase of the USD/IDR (depreciation) will then push domestic interest rate to increase.
\end{abstract}

\section{Introduction}

As a consequence, adopting floating exchange rate, many countries face often widely fluctuation and large movements of their exchange rates as capital flows freely coming in or out the countries. This phenomenon could move market exchange rates away from their fundamental value (exchange-rate misalignment). Indeed, freely floating exchange rate system is needed by independent monetary authority to conduct independent monetary policy. However, persistent exchange-rate volatility and misalignment will exacerbate inflationary pressures and financial sector vulnerabilities. For many countries, these impacts are not welcomed and they will take some measures to mitigate those.

Indonesian foreign exchange market has been developing in conjunction with changes in the exchange rate system, which has moved gradually toward increased emphasis on market mechanisms. This development has been playing a significant role in USD/IDR movements as the exchange rate will response instantly to external shocks. Previously, the Indonesia foreign exchange system was operated in tight government control. Since adopting free-floating exchange rate when financial crises erupted in August 1997, Indonesia has been experiencing of rapid fluctuation of the rupiah. As adopting free floating exchange-rate regime and its position as a small open economy, Indonesia' exchange rate movements are strongly influenced by capital flows and net export's proceeds. Hence, existence of central bank optimal monetary policy response is needed to drive the exchange rate for the long-term equilibrium exchange rate as well as to maintain its stability. Then central bank through monetary policy can influence the exchange rate in the short or even in the long run. In the long term, monetary policy can affect exchange rate indirectly through changes in respected domestic macroeconomic variables such as inflation, productivity, and the current account (Moentjak, 2006). Meanwhile, in the short run, monetary policy is able to influence foreign-exchange markets expectations (foreign-exchange market microstructure).

Within Enhanced inflation targeting framework (EITF), inflation target is the main objective to support sustainable economic environment, and is determined by several factors. One of the significant factors is exchange rate through its power of pass through effect on domestic inflation. In addition to maintain the optimal range of the exchange rates, the exchange rate should be stable enough in order to boost the international trade and hence domestic economy. Thus, the effort to set optimal exchange rate and maintain exchange rate stability (reflected with low exchange rate fluctuations) is also main duty of the monetary authority which adopts ITF in order to achieve its objective of price stability.

As Enhanced Inflation Targeting Framework (EITF) chosen by Bank Indonesia, one of monetary operation instrument chosen is short term policy interest rate i.e. reverse repo rate or deposit facility rate. Setting appropriate policy interest rate to drive actual inflation to its target and implicitly desired economic growth is important for the central bank who adopt inflation targeting framework. Besides, while exchange rate has a significant influence to inflation and the economy, the central bank has a duty to manage it properly.

\section{The Exchange Rate and Monetary Response}

The relationship between exchange rate, inflation, and interest rate, is very closed in the economics perspective. Therefore, any monetary policy action to affect one of these three variables will affect not only the variable but will also indirectly affect the other two. Any attempt to move any two pairs of variables in opposing directions will not sustainable in the long run (Moentjak, 2014). For example, he explained when the central bank wants to hike interest rates to keep inflation down. The policy cannot at the same time keep exchange rate weak in order to stimulate exports. Raising interest rate to tame inflation while keeping the exchange rate fixed, the central bank is 
violating UIP. Such a scheme may become self-defeating for the central bank, since the higher interest rates will attract more foreign capital, increasing the demand for domestic currency, then affect domestic currency appreciation. Meanwhile, as the central bank wants to fix the exchange rate, the central bank will have to intervene in the foreign exchange market by injecting money into the domestic economy to satisfy the greater demand for domestic currency by implementing FX buying intervention policy will then increase its official foreign reserve. However, the injection of money will defeat the initial purpose of the hike in interest rates, to reduce inflation.

It is commonly agreed that foreign-exchange intervention should be consistent with the stance of monetary policy for two reasons at least i.e exchange rate stability and exchange rate alignment to support inflation target. Complemented with interest rate, the two kind monetary policies should support each other to achieve the desired monetary policy's objectives such as price stability or exchange-rate stability for countries which adopt ITF policy (Mohanty, 2013). Without this stance, he argues that any inconsistency between the monetary policy stance and the exchange rate may reduce the effectiveness in achieving these objectives. With regard to exchange-rate stability objective, exchange-rate intervention may have good result to stabilize the exchange rate but without no costs. For example, when appreciation trend exists, foreign-exchange buying intervention can create high costs as the central bank should withdraw the additional excess money supply (caused by the intervention) by selling more central banks bills, in order to halt domestic price increases. These dual actions will create more costs as negative margin commonly exists. Nevertheless, central banks purchasing intervention policy in this regards will obviously accumulate more official reserve that can be effective in improving sovereign credit ratings and reducing external shocks impact.

On the other hand, the macroeconomic effects of intervention depend on the composition of banks' portfolios (Vargas et. al, 2013). When banks hold more government bonds than their optimal portfolio from a long-term portfolio perspective, they will try to reduce the lending rate to increase loan assets until the level meets the desired loan-to-investment ratio. This is called portfolio diversification to minimize risk against 'Lazy Bank' phenomenon. This is indicated by an expansion of bank lending. There is interesting phenomenon that whenever central banks issuing large amounts of short-term securities to sterilize their foreign-exchange reserve purchases, the average maturity of their securities has shrunk to less than one year since 2000, although the EM governments have increased the average maturity of their debt as reported by Bank for International Settlements in its 2005 report (Mohanty and Berger, 2013). Generally, the interest of the central bank bills is higher than foreign assets bought by the central bank and hence negative spread exists and deteriorate central bank's balance sheet. Several studies also find similar results that central banks perform large-scale buying foreign-exchange interventions to resist domestic currency appreciation, and then respectively withdraw the additional domestic liquidity by issuing shortterm debt. This monetary operation called sterilized foreign-exchange intervention will inflate central banks monetary costs and potentionaly commercial bank balance sheets with expansionary implications for the economy. High cost of intervention could erode not only a central bank's credibility but also their financial strength which halt to deliver on the price stability objective.

In principle, interventions in the foreign exchange market should be designed to complement the stance of monetary policy. Flug and Shpitzer find Israel high interest rate cuts by the central bank combined with a buying foreign exchange intervention to resist appreciation were reasonably successful in reducing the risk of recession during the 2008 global crisis (Mohanty, 2006). Meanwhile, thightening central bank policy when economy recovering in the face of rising inflation expectations, generate strong capital inflow that appreciate domestic currency. Then the central bank performs buying foreign-exchange intervention to resist appreciation. Consequently, domestic liquidity increases which should be withdrawn by the central bank at the cost of central bank. At the same time, exchange rate depreciation (or at least not appreciate will be shifted as burden of adjustment to the external sector). Study in Peru finds that foreign exchange purchase by the central banks should be sterilized in order to keep the interbank interest rate at the policy target level (Armas, 2005). This sterilized intervention policy imply some additional costs burdened to the central bank.

In BIS paper, Korea's experience dilemna of strong capital inflows and high inflation periode push the central bank to increase interest rates to fight inflation will attract further inflows and ignite further currency appreciation pressures whereas reducing interest rates to limit capital inflows will ignite higher inflation (Ryoo and Kwon, 2013). Therefore, they suggest that foreign-exchange intervention can help to stem inflows attracted by selffulfilling expectations of currency appreciation. Some central banks prefer delivering strategic communication to avoid any market perception that foreign exchange intervention is inconsistent with monetary policy. Meanwhile, another central banks have been announcing their foreign exchange intervention with a view to send a correct signal to this effect.

Regarding to monetary response to exchange-rate dynamics, most modern central banks also implement shortterm policy interest rate policy to guide exchange rate to the level as desired. Furthermore, this short-term policy interest rate as response to misaligned exchange rates to achieve desired price (inflation) level and desired economic growth is measured by monetary policy rule i.e. Taylor rule. In BIS Paper, monetary policy rule confirms that there has been a interest rate response by the central bank to exchange rate fluctuations, over and above its effects on expected inflation, but smaller than the reaction to output (Schmidt-Hebbel and Tapia, 2002) and (Cuth, 
2003). They also explained that monetary policy responds to exchange rate shocks should depend on foreign capital regime, foreign-exchange intervention policy option, official foreign reserve, and persistence of the exchange rate volatility. The other important factor is central bank credibility. Central bank credibility will decrease the probability of persistent exchange rate shock affects on inflation, as the public will expect authorities to support price stability. In a floating exchange rate regime, a central bank only should response on exchange rate fluctuations only if they impact the rate of inflation persistently in the policy horizon. Central bank should not response temporary exchange-rate shock for example by increasing interest rate because it is costly. Conversely, the central bank should take monetary measures to prevent persistent volatility and misalignmend in the exchange rate otherwise it will lead to inflationary pressures through monetary tightening.

In monetary transmission channel mechanism, exchange rate plays a significant role in many countries especially emerging economies. This is proven by (Grenville, 1995); (Thiessen, 1995), in their paper. In the fundamental exchange rate theory called uncovered interest parity (UIP), exchange rate dynamics depend on interest rate differential between countries. Central bank's unanticipated interset rate increase of 25 basis points, is found to appreciate the exchange rate approximately 0.35 per cent, with results for the individual countries ranging from $0.25-0.50$ of a per cent (Kearns and Manners, 2005). They also find that changes in interest rate policy have substantially different effects on the exchange rate depending on how they alter expectations regarding future interest rate policy. For example, an unanticipated interest rate increase of $25 \mathrm{bps}$ appreciates approximately $0.35 \%$ of the exchange rate movement generally. Surprises that changes in future interest rate policy will appreciates $0.4 \%$, while do not change future interest policy expectations only appreciates $0.2 \%$.

\section{Research Methodology}

\subsection{Variables and Data}

This research used monthly data from 2000-2013. Data derived from CEIC, SEKI, and internal data of the Bank of Indonesia. For the quarterly data, interpolation was used in order to obtain monthly data. The variables were in the form of natural logarithm, except the rate or percentage variables. In order to embody the long-run relations (equation 1) to (equation 5) within a suitable macro-econometric model, it is important that the orders of integration of the core variables in the theoretical model are ascertained. More specifically, given the econometric methods this research employs, this research wishes to ensure that the variables used in the empirical analysis suggested to be $I(1)$ variables. The variables under consideration are $l i s p r_{-} c a p_{t}, l m r 1_{-} c a p_{t}, r e_{-} i d_{t}, l y r i d_{-} c a p_{t}, l p_{-} i d_{t}, l w r_{-} i d_{t}, l s r_{-} i d_{t}$, $\overline{\text { yrldcap }}_{t} l r_{-} u s_{t}^{*}, l p_{t}^{*}$. The results suggest that it is reasonable to treat lispr_capt $, l m r 1_{-} c a p_{t}, r e_{-} i d_{t}$, $l y r i d_{-} c a p_{t}, l p_{-} i d_{t}, l w r_{-} i d_{t}, l s r_{-} i d_{t}, l y r l d c a p_{t} l r_{-} u s_{t}^{*}, l p_{t}^{*}$ as $I(1)$ variables. It is useful to transform variables a priori to get variables that are I(1) rather than dealing with mixtures of I(1) and I(0) variables directly (Haldrup, 2012). The variables used in this research are as follows:

1) Real GDP per capita (LYRID_CAP)

The original data is in quarterly form, which was then interpolated to monthly data by using the Quadratic Math Sum. The base year used was 2005 .

2) Potential Output (LYRIDCAP_POT)

A series of potential outputs was obtained by using the Hodrick-Prescott filter.

3) Domestic Price level (LP_ID)

The real data was the Consumer Price Index (CPI) with 2005 as the base year, which was then deducted by oil price.

4) Real Money Demand per capita $\left(L M R 1_{-} C A P\right)$

This was meant to see the implication of the non-cash payment increase towards M1.

5) Real Payment System Innovation per capita (LISPR_CAP)

In this case, the variable used is the amount of payment transaction value using non-cash instruments, both account-based and card-based, such as clearing, RTGS, debit card, and credit card. The non-cash payment data (especially RTGS) used still included the clearing settlement result. However, keeping in mind that the clearing settlement amount is relatively constant and less significant, it was estimated that there is no implication for research results. Besides this, the credit card portion of the non-cash payment variable is relatively low, namely $0.1-0.3 \%$ of the total non-cash payment transaction value.

6) Real domestic Interest rate (RE_ID)

The interest rate used was the real o/n interbank money market as a proxy of CB's policy interest rate.

7) Real wages (LWR_ID)

The original data was quarterly data, with some missing values. Interpolation was then conducted in order to obtain data for the full quarterly observation period, which was then transformed into monthly data.

8) Real exchange rate (LSR_ID) 
In the form of the Rupiah exchange rate per USD multiply by relative price. According to this definition, the real exchange rate can be defined in the long run as the nominal exchange rate (e) that is adjusted by the ratio of the foreign price level $(\mathrm{Pf})$ to the domestic price level $(\mathrm{Pd})$. Mathematically, it can be shown as $\mathrm{sr}=\mathrm{s} *(\mathrm{Pf} / \mathrm{Pd})$. In terms of this definition, the decline in the SR can be interpreted as the real appreciation of the exchange rate.

9) International interest rate level ( $\left.R E_{-} U S\right)$

The international interest rate used was the interest rate of the US Federal Reserve.

10) International price level (LP_US)

The US CPI was used as the representation of the international price level then deducted by oil price.

\subsection{Methodology}

This study attempts to forecast the response of monetary policy on foreign-exchange shocks in Indonesia using a structural VAR (SVAR) approach. SVARs are defined as a multivariate time series model which shows linear representation of a vector of observable variables on its own lags (Sharifi and Renan, 2010). These models are economically interpretable simplifications of VAR models where some economic theory is referred to set the identification restrictions. SVAR model can be used to identify the shocks from respected endogenoeous variables (Lutkepohl and Kratzig, 2004).

As ITF chosen by Bank Indonesia, one of monetary operation instruments chosen to achieve ultimate objective i.e. domestic price is short-term policy interest rate. Determing optimal interest rate as response to the exchange rate is one policy tool of the central bank in driving the actual inflation closed to its target and implicitly desired economic growth. The policy interest rate, in this regard, may also significant role to drive the exchange rate to its aligned level (meet inflation target). In order to see the impact of policy interest rate to exchange rate dynamics as well as the impact of exchange-rate dynamics to macroeconomic indicators, this research implements Structural Cointegrating Vector Auto Regression (SC-VAR) in an open economy model proposed by Garrat et al. (1999) and followed by Syarifuddin et al. (2009) that may able to solve the problem. In the model, this research applies five long-run structural equations which includes payment system innovation equation, real money demand equations, aggregate demand equation, purchasing power parity, and interest rate parity equation.

This method was selected because the VAR-based estimation was appropriate to describe the simultaneous relationship among variables. Keeping in mind that some of the variables were not stationery, even though there is a long-term connection among the variables, the cointegration partnership needed to be accommodated. Some literature referred to in using this method were Harris (1995), Boswijk and Doornik (2003), Garratt, Lee et al. (1999), as well as Kapetanios et al. (2000).

The strength of Structural Cointegrating VAR over other estimation methods is its accommodation of theoretical foundation, behavioral relationship, and flexible dynamics. This is different from Structural VAR, which is unable to identify long-term relationships among variables. Unlike Vector Error Correction Model (VECM), where the long-term relationship is decided by the cointegration of data, in Structural Cointegrating VAR, the long-term relationship is built on the previous empirical studies and theories and the cointegration relationship among their variables.

Structural Cointegrating VAR begins by defining the long-term structure, then inserting the long-term relationship into an unrestricted VAR model. This is unlike the traditional approach, which begins with an unrestricted VAR, then its cointegration is sought based on data, which of course does not have a clear direction, for the Structural Cointegrating VAR cointegration set at the outset.

This cointegrating SVAR will use monthly data from 2000-2013. Data derived from CEIC, SEKI, and internal data of the Bank of Indonesia. For the quarterly data, interpolation was used in order to obtain monthly data. The variables were in the form of natural logarithm, except the rate or percentage variables. The equations, variables, and data used in this research according to Garrat, Lee et al. (1999) augmented payment system innovation equation. In this model of the monetary response on exchange dynamics, there are five long-term relationships which can be formulated as follows:

$$
\begin{aligned}
& l i s p r_{-} c a p_{t}-l p_{i d_{t}}-\text { lyrid_cap }_{t}=\alpha_{10}+\alpha_{11} t+\beta_{13} r e_{-} i d_{t}+\varepsilon_{1, t+1} \\
& \operatorname{lmr} 1_{\text {cap }_{t}}-\text { lyrid }_{\text {cap }} p_{t}-l p_{i d_{t}}=\alpha_{20}+\alpha_{21} t+\beta_{21} \text { lispr }_{\text {cap }}+\beta_{23} r e_{-} i d_{t}+\varepsilon_{2, t+1} \\
& \text { lyrid }_{\text {cap }_{t}}-\text { yridcap }_{\text {pot }} t=\alpha_{30}+\alpha_{31} t+\beta_{31} r e_{i d_{t}}+\beta_{36} l w r_{-} i d_{t}+\varepsilon_{3, t+1} \\
& l p_{-} i d_{t}-l p_{-} u s_{t}^{*}-\text { srid_g }_{t} \quad=\alpha_{40}+\alpha_{41} t+\varepsilon_{4, t+1} \\
& \text { re_id } e_{t}-r e_{-} u s_{t} \quad=\alpha_{50}+\alpha_{51} t+\text { srid }_{-} g_{t}+\varepsilon_{5, t+1}
\end{aligned}
$$

where:

- $\quad$ lispr_cap $\quad=\log$ form of real payment instrument innovation per capita

- $\quad l p_{i d_{t}}$

$=\log$ form of consumer price index

- lyrid_cap $_{t} \quad=\log$ form of real output per capita 
- $\quad l m r 1_{-} c a p_{t} \quad=\log$ form of money supply per capita

- lwrid = log form of real wage on average

- $\quad$ yridcap_pot = real output per capita potential in log form

- $l p_{-} u s_{t}^{*} \quad=\log$ form of US consumer price index

- $r_{-} i d_{t} \quad=$ real cost of domestic capital (IDR interest rate)

- $r e_{-} u s_{t} \quad=$ real cost of US capital (USD interest rate)

- $\quad$ srid $g \quad$ = growth real exchange rate

The five structural equations can be described as follows:

a) Equation 1 shows that total of the long-term real non-cash payment is determined by the amount of national income and advanced technology, which shown by the time trend. Meanwhile, the total short-term non-cash payment is also affected by the real domestic o/n interest rate (Baumol, 1952) and (Tobin,1956).

b) Equation 2 shows the representation of real money demand equation, which shows that the real M1 money demand is determined by the domestic real o/n interest rate and real GDP. In the short-term period, money demand is also affected by non-cash payment variables.

c) Equation 3 is the representation of aggregate demand equation, which shows that the long-term real GDP per capita with the current potential output is determined by the real cost of capital (interest rate), the level of real wages, and the technological change. It can be seen that in the long term, only the real variable affects the real GDP. Meanwhile price and other nominal variables have short-term effects.

d) Equation 4 shows Purchasing Power Parity (PPP).

e) Equation 5 shows Interest Rate Parity (IRP).

The five long-term partnerships (equation 6) can be written as follows:

$$
\varepsilon_{t}=\beta^{\prime} z_{t-1}-\left(\alpha_{0}-\alpha_{1}\right)-\alpha_{1} t
$$

where:

$$
\begin{aligned}
z_{t}= & \left(\text { lispr }_{\text {cap }}, l m r 1_{\text {cap }}, r e_{i d_{t}}, l y r i d_{c a p}, l p_{i d_{t}}, l w r_{i d_{t}}, \text { srid }_{g_{t}}\right. \\
& \text { lyridcap_pot,re_us } \left., l p_{t} u s_{t}\right) \\
\alpha_{0}= & \left(\alpha_{10}, \alpha_{20}, \alpha_{30}, \alpha_{40}, \alpha_{50}\right)^{\prime}, \alpha_{1}=\left(\alpha_{11}, \alpha_{21}, \alpha_{31}, \alpha_{41}, \alpha_{51}\right)^{\prime}, \text { and } \\
\varepsilon_{t}= & \left(\varepsilon_{1 t}, \varepsilon_{2 t}, \varepsilon_{3 t}, \varepsilon_{4 t}, \varepsilon_{5 t}\right)^{\prime}
\end{aligned}
$$

and also

$$
\beta^{\prime}=\left(\begin{array}{cccccccccc}
1 & 0 & -\beta_{13} & -1 & -1 & 0 & 0 & 0 & 0 & 0 \\
-\beta_{21} & 1 & -\beta_{23} & -1 & -1 & 0 & 0 & 0 & 0 & 0 \\
0 & 0 & -\beta_{33} & 1 & 0 & -\beta_{36} & 0 & -1 & 0 & 0 \\
0 & 0 & 0 & 0 & 1 & 0 & -1 & 0 & 0 & -1 \\
0 & 0 & 1 & 0 & 0 & 0 & -\beta_{57} & 0 & -1 & 0
\end{array}\right) .
$$

Matrix $z_{t}$ is divided into $z_{t}=\left(q_{t}^{\prime}, v_{t}^{\prime}\right)^{\prime}$ where $q t$ is for endogenous variables and $v t$ is a weakly exogenous variable towards that equation system. This will be decided later based on testing.

The next stage is to insert $\varepsilon_{t}$ into the equation (7) as follows:

$$
\Delta q_{t}=-\Phi \varepsilon_{t}+\sum_{i=1}^{s-1} \Gamma_{i} \Delta_{z_{t-i}}+\Psi \Delta_{v_{t}}+u_{t}
$$

where:

$\Phi=$ = error correction coefficient matrix

$\Gamma_{i} \quad=$ short-run coefficient matrix

$\Psi \quad=$ vector shows the effect of weakly exogenous variable

$u_{t} \quad=$ serially uncorrelated shocks vector

The equation shall be elaborated as follows (equation 8):

$$
\Delta q_{t}=\Phi\left(\alpha_{0}-\alpha_{1}\right)+\Phi \alpha_{1} t-\Phi \xi_{t}+\sum_{i=1}^{s-1} \Gamma_{i} \Delta_{z_{t-i}}+\Psi \Delta_{v_{t}}+u_{t}
$$

Where $\xi_{t}=\beta_{z_{t-1}}$ : error correction terms 


\section{Result and Discussion}

\subsection{Variable Description}

Before conducting various procedures in estimating and forecasting by using SC VAR, there is a description of the variables used and the relationship among those variables. The amount of lispr_cap, lkartalr_cap, lmrl_cap variables tends to rise over time. The trend of the $i s p r \_c a p$ variable increase occurs in line with the development of technology which enabled the development of non-cash payment instruments and its availability in many places. Meanwhile, the stochastic movement from the lispr_cap variable is related to the short-run factor which influences it, among other things in line with the fluctuation of real GDP per capita (lyrid_cap). The increasing trend of lmr1_cap variables is in line with the real GDP per capita increase trend. The stochastic movement of both variables is affected by the real GDP per capita and domestic real interest rate (re_id).

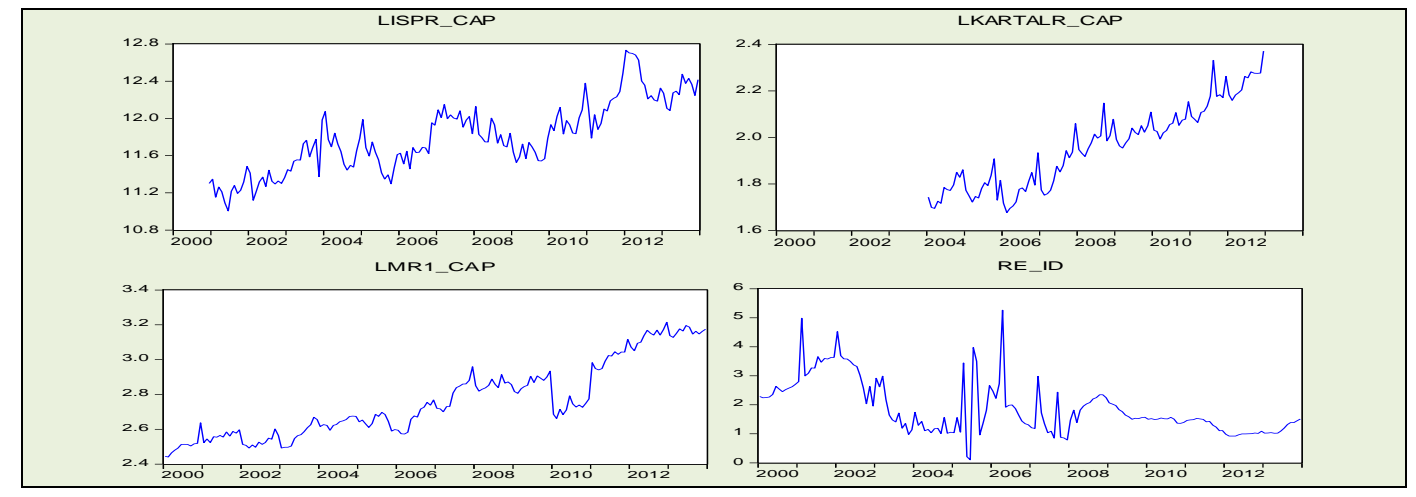

Figure 1. Variables Chart Source: Own Calculation

For the real GDP per capita variable (lyrid_cap), there is a cyclical factor, especially at the end of the year, which is shown by expansionary movement, which is then followed by a contraction in the following period. Meanwhile, there is an increasing trend for the $l p \_i d$ variable which shows that there is a continuous price hike since 2008. The behavior of the real exchange rate growth (srid_g) variable is volatile, but the real wage variable $(l w r i d)$ could be seen to tend to increase. As shown in the Figure 1, the amount of currency per capita (lkartalr_cap) and real non-cash payments per capita (lispr_cap) tended to increase during the analysis period.

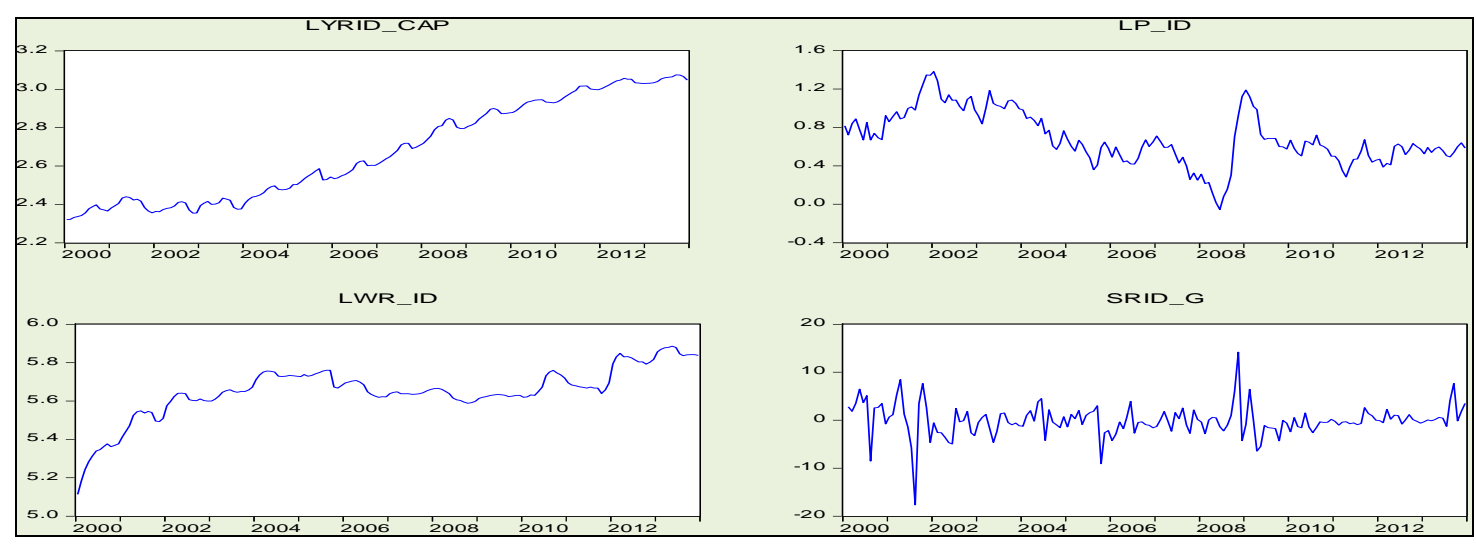

Figure 2. Development of the Variables Source: Own Calculation

Impact of non-cash payment Increase on the Economy and Its Implication for Monetary Control in Indonesia. The amount of lispr_cap, lmrl_cap variables tends to rise over time. The trend of the lispr_cap variable increase occurs in line with the development of technology which enabled the development of non-cash payment instruments and its availability in many places. Meanwhile, the stochastic movement from the lispr_cap variable is related to the short-run factor which influences it, among other things in line with the fluctuation of real GDP per capita (lyrid_cap). The increasing trend of $l m r 1 \_c a p$ variable is in line with the real GDP per capita increase trend. The stochastic movement of both variables is affected by the real GDP per capita and the domestic over nite $(\mathrm{o} / \mathrm{n})$ real interest rate $(r e$ id $)$.

For the real GDP level variable (lyrid_cap), there is a cyclical factor, especially at the end of the year, which is shown by expansionary movement, which is then followed by a contraction in the following period. Meanwhile, there is an increasing trend for the $l p \_i d$ variable which shows that there is a continuous price hike during the 
observation period. The behavior of the real exchange rate growth (srid_g) variable is fluctuated with decreasing trend (appreciation), but the real wage variable ( $\left.l w r_{-} i d\right)$ could be seen to tend to increase (see Figure 2).

\subsection{Estimation Result of Structural Cointegarting VAR}

The result of Structural Cointegrating VAR estimation is 2 lags, 5 cointegration equations with intercept and trend on its cointegrating equation, but no trend on its VAR, with restrictions on its long-term structural equation coefficient as mentioned earlier. This shows that the restriction is able to identify all cointegrating vectors and its LR statistic is 115.73 with $0.0000 \mathrm{p}$-value.

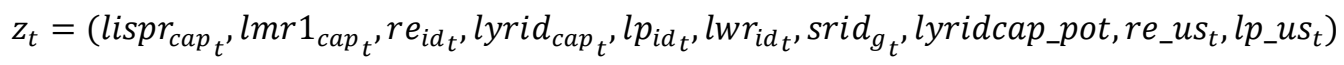

\begin{tabular}{|l|l|c|c|c|}
\hline \multicolumn{1}{|c|}{$H_{0}$} & $H_{1}$ & Test Statistics & 95\% Critical values & Prob.** \\
\hline$r=0^{*}$ & $r \geq 1$ & 595.9454 & 273.1889 & 0.0000 \\
$r \leq 1^{*}$ & $r \geq 2$ & 404.9796 & 228.2979 & 0.0001 \\
$r \leq 2^{*}$ & $r \geq 3$ & 296.9512 & 187.4701 & 0.0000 \\
$r \leq 3^{*}$ & $r \geq 4$ & 217.2547 & 150.5585 & 0.0000 \\
$r \leq 4^{*}$ & $r \geq 5$ & 159.1532 & 117.7082 & 0.0000 \\
$r \leq 5^{*}$ & $r \geq 6$ & 107.6824 & 88.80380 & 0.0011 \\
$r \leq 6^{*}$ & $r \geq 7$ & 75.80433 & 63.87610 & 0.0036 \\
$r \leq 7 *$ & $r \geq 8$ & 50.31634 & 42.91525 & 0.0077 \\
$r \leq 8^{*}$ & $r=9$ & 30.16454 & 25.87211 & 0.0137 \\
$r \leq 9$ & $r=10$ & 11.75949 & 12.51798 & 0.0667 \\
\hline
\end{tabular}

\footnotetext{
Trace test indicates 9 cointegrating eqn(s) at the 0.05 level

*Denotes rejection of the hypothesis at the 0.05 level

**MacKinnon-Haug-Michelis (1999) p-values
}

\section{Table 1. Unrestricted Cointegrating Rank Statistics for the Model (Trace Statistics)}

As mentioned earlier, (restricted cointegration test), the rejection of this restriction is much more to the possibility of an inappropriate amount of the cointegrating equation (because there is an $\mathrm{I}(0)$ variable), keeping in mind the restriction on the cointegration equation was identified and binding. The coefficient of the variables are significant, which can be seen from its t statistic, which is greater than two.

a. Maximum Eigenvalue Statistics

\begin{tabular}{|l|l|c|c|c|}
\hline \multicolumn{1}{|c|}{$H_{0}$} & \multicolumn{1}{|c|}{$H_{1}$} & Test Statistics & 95\% Critical values & Prob.** \\
\hline$r=0^{*}$ & $r \geq 1$ & 190.9657 & 68.81206 & 0.0000 \\
$r \leq 1^{*}$ & $r \geq 2$ & 108.0284 & 62.75215 & 0.0000 \\
$r \leq 2^{*}$ & $r \geq 3$ & 79.69652 & 56.70519 & 0.0001 \\
$r \leq 3^{*}$ & $r \geq 4$ & 58.10156 & 50.59985 & 0.0071 \\
$r \leq 4 *$ & $r \geq 5$ & 51.47075 & 44.49720 & 0.0075 \\
$r \leq 5$ & $r \geq 6$ & 31.87808 & 39.33101 & 0.2282 \\
$r \leq 6$ & $r \geq 7$ & 25.48799 & 32.11832 & 0.2589 \\
$r \leq 7$ & $r \geq 8$ & 20.15181 & 25.82321 & 0.2345 \\
$r \leq 8$ & $r=9$ & 18.40504 & 19.38704 & 0.0690 \\
$r \leq 9$ & $r=10$ & 11.75949 & 12.51798 & 0.0667 \\
\hline
\end{tabular}

Max-eigenvalue test indicates 5 cointegrating eqn(s) at the 0.05 level

*Denotes rejection of the hypothesis at the 0.05 level

**MacKinnon-Haug-Michelis (1999) p-values

Table 2. Unrestricted Cointegrating Rank Statistics for the Model (Maximum Eigenvalue Statistic)

The SC-VAR result of the five long-term structural equations summarized from the Eviews output, is as follows:

$$
\begin{aligned}
& \text { lispr_cap }-l p \_i d-l y r i d \_c a p \quad=6.38+\mathbf{0 . 0 1 t}+\mathbf{0 . 5 8 r e} \text { id } \\
& \text { lmrl_cap-lyrid_cap-lp_id } \quad=-6.52+\mathbf{0 . 0 1 t}+\mathbf{0 . 3 7 r e} \text { id }+\mathbf{0 . 4 2 l i s p r} \text { _cap } \\
& \text { lyrid_cap-lyridcap_pot } \quad=0.18-\mathbf{0 . 0 1 r e \_ i d - 0 . 0 2 l w r} i d \\
& l p \_i \bar{d}-l p \_u s-l s r \_i d \quad=1.40-\mathbf{0 . 0 1 t} \\
& \text { re_id - re_us } \\
& =2.37-\mathbf{0 . 0 1 t}+0.03 \text { srid } \_g
\end{aligned}
$$

Signs from some coefficients in long-term structural equations were seen to be in line with the theoretical framework. In equation 9, the trend component on structural equations was seen to be positive as these show increasing trends. Meanwhile, the re_id coefficient score was relatively high, which showed that the lispr_cap variable movement was highly influenced by the $r e \_i d$ variable positively. It means that the society prefer using non-cash instrument in payment while interest rate increasing as they deposit their money in banks as demand/saving deposit. Thus, they can earn interest from the deposit but not losing their liquidity needs. $r e \_i d$ is one of best proxy central bank's policy rate because they have closed relationship. Meanwhile, it needs to be noted that the positive trend is not trend upon the lispr_cap variable itself, but a trend in the context of the cointegration relationship between the lispr_cap variable and other variables. As mentioned earlier, based on lispr_cap series visualization, a positive time trend upon the lispr_cap variable itself was observed.

In money demand equation 10 , the long-term real money demand was also affected by the market o/n rate interest rate $\left(r e \_i d\right)$, whose amount continuously increased. The increase of the re id will increase real money demand. 
This may be caused by increasing of society's preferences in using non-cash's payment instrument as explained before. Meanwhile, in aggregate demand equation 11, the re_id increase will reduce the real GDP per capita. This is of course related to the investment decrease in line with the increasingly higher cost of capital. Negative real wages $\left(l w r_{i} i d\right)$ variable coefficient shows that the increase of real wages will actually decrease the real GDP per capita (lyrid_cap). This shows that the impact of labor demand increase through real wage increases is higher than labor productivity increase due to rising real wages, so that the net effect takes the form of decreasing real GDP. The trend component on the structural equation was seen to be positive, despite having a relatively low coefficient. The last two equations 12 and 13 respectively show the Purchasing Power Parity (PPP) and Interest Rate Parity (IRP). Within PPP rule, exchange-rate dynamic has closed relationship with inflation deviation. In this respect, exchange-rate pass trough can be explained empirically to measure how significant the relationship between exchange rate and inflation gap.

However, there may some reasons why the relationship is not significant or have a little relation. One of them is the role of central bank's monetary credibility. Akofio-Sowah (2007) find supporting evidence of this phenomenon. He reveals that developing countries that operate credible monetary regimes, and have low inflation, also experience a lower degree of exchange rate pass through. In this respect, Bank Indonesia should raise its monetary credibility to avoid exchange rate dynamics shock to domestic inflation as a consequence. The IRP equation explained that the increased real exchange return (depreciation) is followed by increasing in real domestic o/n interbank interest rate insignificantly. It means that the domestic currency depreciation will push the central bank to increase policy interest rate followed by domestic real $\mathrm{o} / \mathrm{n}$ interbank interest rate (re id) slightly in order to prevent further domestic currency depreciation though it is not significant. The small coefficient of real exchange rate is common in a country which adopts ITF. The central bank of the country generally would be more aggressive to inflation gap than exchange rate misalignment. Many countries with poor institutional quality have small coefficient of interest rate differential to response exchange-rate misalignment caused by speculative attacks (Fernandez, 2005). Even though has a small coefficient, the policy interest rate is still used and effective to drive the misaligned exchange rate to its fundamental value.

However, there are still debates to what kind of monetary defense against currency pressure (especially when facing exchange-rate crisis). Jeon (2002) find evidence to justify what kind of monetary stance central bank should pursue: tightening or accommodative in the face of currency crises. Using VAR and SVAR approach, he finds that in addition to IMF's rescue financing, the tight monetary policy (imposing high interest rate) was not necessary to stabilize exchange-rate massive depreciation. On the contrary, an expansionary monetary policy may stabilize the misaligned exchange rate as well as experiencing a milder recession.

To defense exchange rate from crises by the central bank in economic theory can be a part of a fear of free floating syndrome. Fear of Free Falling (FFF) which is reflected in decisive capital outflow would ignite domestic currency depreciation. Then central bank would respond with raising interest rates to defend the domestic currency. Thus, FFF would measure how responsive the central bank in mitigating capital outflow impact in this regard. Recently, as capital markets plays greater role in financial market, the effect of monetary policy to exchange rate is in fact showing decreasing trend. Thus it is a normal phenomenon when monetary response on exchange rate in Indonesia is insignificant recently as capital market shows greater role in financial instrument. The result is also supported by Park (2011) who investigate monetary response on exchange rate using the small open economy DSGE model in the case of Korea. He finds interesting evidence that the Bank of Korea is not responsive to exchange-rate dynamics but is more sensitive to inflation deviation. This policy is common as the Bank of Korea implement ITF as monetary framework. Another finding also supports this result. Anaraki (2001) finds interesting phenomenon such a characteristic in G-7 countries where capital markets play significant role in their own respected country. Using the cholesky forecast variance decomposition technique and impulse response functions, they show that monetary policy affects exchange rate dynamics indirectly through the pass through effect on stock market (through dividend yields, rather than through policy interest rate 'fed fund rate' in US.

Meanwhile the error correction coefficient matrix $(\Phi)$ of some variables becoming the focus of this research are lispr_cap, lmr1_cap, re_id, lyrid_cap, and lp_id, as shown in Appendix. Some of the error correction coefficients are significant, but some others are not. Cointegrating equations 1 , and 2 are significantly influenced $d\left(l i s p r \_c a p\right)$. Meanwhile, cointegrating equations 1, 2, and 3 significantly affected $d\left(l m r 1 \_c a p\right)$. Besides, cointegrating equations 2 and 3 were significantly affecting $d(r e$ id $)$. However, the significant score of $d$ (lyrid_cap) was affected by cointegrating equations 3 . Meanwhile, the $d\left(l p_{-} i d\right)$ score was merely affected by cointegrating equation 3 and 5 .

\section{Generalized Impulse Response}

In order to obtain a graphic of the influence of the real exchange rate $\left(l s r_{-} i d\right)$ towards money demand, output, inflation and its implication for the Bank of Indonesia policy as reflected by domestic o/n real interest rate (re id), the generalized impulse response is simulated. From that generalized impulse response, it was seen in Figure 28 that the shock of real exchange rate (srid_g) on the IRP equation for 1 standard deviation (0.4392) will decrease 
real non-cash instrument payment per capita (lispr_cap) before increase after 4 periods, real money demand (lmrl_cap) will decrease after two period increase, real output per capita (lyrid_cap) will be volatile after increasing in 1 period, and real wages $\left(l w r_{-} i d\right)$ will increase after one period decrease.

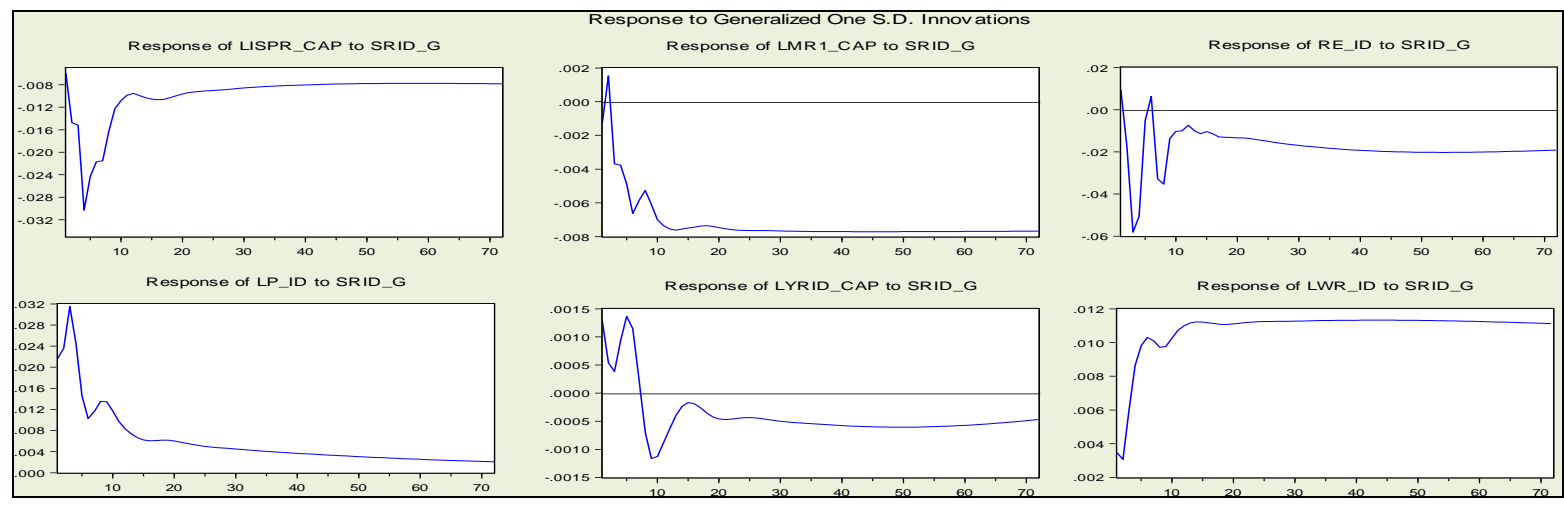

Figure 3. Generalized Impulse Response Source: Own Calculation

Meanwhile, the shock of real exchange rate will increase domestic price and after 3 periods its impact is decreasing. Meanwhile it will instantly increase domestic real o/n interbank interest rate (re_id) for a while before decreasing until two period and then increase the next period before decreasing again followed rise and down with smaller fluctuation. It can be seen that its influence on some variables are not convergent, even up to 72 months, which indicates that there is a persistent influence of the srid $g$ shock variable towards the 5 variables.

\section{Forecast Error Variance Decomposition (FEVD)}

To see the share/contribution of each endogenous variable shock to another within SCVAR model, forecast error variance decomposition (FEVD) analys is applied. Through these procedures, each shock's role on the variance of an endogenous variable in the VAR system can be known. The result showed that variance of the interest rate variable (re_id) was highly influenced by lagged itself followed by non-cash payment (lispr_cap), real money supply (lmrī_cap), real output (lyrid_cap,domestic price (lp_id) and real exchange rate (srid_g) shock variables. However, real exchange-rate shock (srid_g's influence on interest rate re id) is in increasing path. It can be viewed in Table 14 , the interest-rate shock $\left(r e \_i d\right)$ shock variable mainly affected the macroeconomic variables.

\begin{tabular}{|c|c|c|c|c|c|c|c|c|c|c|c|}
\hline Perio... & S.E. & LISPR_CAP & LMR1_CAP & RE_ID & LYRID_CAP & LP_ID & LWR_ID & SRID_G & LYRIDCAP_... & RE_US & LP_US \\
\hline 1 & 0.131417 & 0.653410 & 0.352909 & 98.99368 & 0.000000 & 0.000000 & 0.000000 & 0.000000 & 0.000000 & 0.000000 & 0.000000 \\
\hline 2 & 0.155114 & 0.968330 & 0.371222 & 96.67357 & 1.365329 & 0.346378 & 0.229331 & 0.003091 & 0.013514 & 0.000711 & 0.028520 \\
\hline 3 & 0.169168 & 4.602511 & 0.380502 & 86.42278 & 1.392862 & 0.503219 & 1.641605 & 0.819969 & 0.039581 & 0.328682 & 3.868288 \\
\hline 4 & 0.185528 & 4.366305 & 0.378099 & 84.95821 & 2.312447 & 0.519336 & 2.008518 & 1.031825 & 0.036740 & 0.395548 & 3.992971 \\
\hline 5 & 0.195433 & 4.234679 & 0.402155 & 83.39220 & 3.046647 & 1.633219 & 1.931559 & 1.082100 & 0.051548 & 0.401919 & 3.823975 \\
\hline 6 & 0.202991 & 5.800177 & 0.397045 & 80.96754 & 3.447702 & 2.111391 & 1.858787 & 1.165635 & 0.062730 & 0.516373 & 3.672627 \\
\hline 7 & 0.209953 & 6.340214 & 0.388611 & 79.75622 & 3.607736 & 2.435104 & 1.964838 & 1.181996 & 0.076762 & 0.667762 & 3.580759 \\
\hline 8 & 0.215988 & 6.316164 & 0.432208 & 78.84462 & 3.560996 & 2.962701 & 2.013991 & 1.227460 & 0.081437 & 1.031385 & 3.529039 \\
\hline 9 & 0.220947 & 6.360450 & 0.463694 & 77.74314 & 3.500369 & 3.479744 & 2.016959 & 1.207980 & 0.082571 & 1.605199 & 3.539892 \\
\hline 10 & 0.225147 & 6.343661 & 0.460746 & 76.73079 & 3.446205 & 4.061975 & 2.023802 & 1.200897 & 0.088119 & 2.161592 & 3.482217 \\
\hline 11 & 0.228740 & 6.268332 & 0.457497 & 75.64748 & 3.398179 & 4.732610 & 2.015601 & 1.200359 & 0.095745 & 2.758459 & 3.425734 \\
\hline 12 & 0.231865 & 6.195023 & 0.451745 & 74.51154 & 3.363196 & 5.361659 & 1.998622 & 1.211072 & 0.101969 & 3.435155 & 3.370015 \\
\hline
\end{tabular}

Table 2. Forecast Error Variance Decomposition Source: Own Calculation

\section{Conclusion}

From the empirical findings above, there are some conclusions. Firstly, using impulse response and structural cointegration VAR approach, a real-exchange rate shock has ambiguous effect on policy interest rate reflected by overnight inter-bank rate fluctuations in the short run. Meanwhile, in the long run, the increase (depreciation) of real exchange growth will push the central bank to raise policy interest rate slightly (reflected by small increased domestic real $\mathrm{o} / \mathrm{n}$ interbank interest rate) in order to halt further exchange-rate depreciation though it is not significant. This conclusion has in fact been done by Bank Indonesia as BI has been often raising policy interest rate whenever USD/IDR is under pressure.

Secondly, from the variance decomposition, it was seen that the shock to the domestic real o/n interbank interest rate was mainly influenced by itself and followed by non-cash payments, money supply, economic growth, inflation and exchange rate shock variables. However, exchange rate's influence on interest rate is in increasing path overtime. Thus it should be considered by the central bank. 


\section{References}

- Akofio-Sowah, 2009. Exchange rate pass-through and the monetary regime in developing countries and emerging economies: is there a link? [Dissertation]. Clark University, Massachusetts (US).

- Anaraki, 2001. How does monetary policy affect the Exchange Rate? Empirical Evidence From G-7 Countries [dissertation]. George Mason University, Virginia (US).

- Armas, 2005. "Forex Intervention in Peru: 2002-2004. Foreign Exchange Market Intervention in Emerging Markets: Motives, Techniques and Implications". BIS Papers, 24, p. 242-254.

- Bank for International Settlements, 2005. "Foreign exchange market intervention in emerging markets: motives, techniques and implications". BIS Papers, 24. p. 1-3.

- Bank for International Settlements, 2013. "Market Volatility And Foreign Exchange Intervention In Emerging Countries: What Has Changed?" BIS Papers, 73, p. 1-10.

- Boswijk and Doornik, 2003. "Identifying, Estimating and Testing Restricted Cointegrated System: an Overview." Disscussion Paper UvA Econometrics University of Amsterdam, 1. p. 1-24.

- Breitung, Bruggemann, Lutkepohl, 2004. Structural vector autoregressive modeling and impulse responses, in Applied Time Series Econometrics, Lütkepohl H, Krätzig M (eds). Cambridge University Press, Cambridge (GB).

- Fernandez, 2005. Three Essays On Current Crises And Defensive Monetary Policy [Dissertation], Texas (US), University of Houston.

- Garrat, Lee, Pesaran, and Shin, 1999. "A Long Run Structural Macroeconomic Model of the UK." Economic Journal, 113, p. 412-455.

- Garrat, et.al, 1999. "A Structural Cointegrating VAR Approach to Macroeconometric Modelling." Working Paper, p. 1-21.

- Grenville, 1995. "The Monetary Policy Transmission Process: What Do We Know? (And What Don’t We Know?)." Reserve Bank of Australia Bulletin. p.15-33.

- Harris, 1995. Using Cointegration Analysis in Econometric Modelling. Prentice Hall, New Jersey.

- Haldrup, et.al, 2012. "Unit roots, Nonlinearities and Structural Breaks".CREATES Research Paper,14, p.134.

- Jeon, 2002. Exploration on alternative monetary policy regimes in post-crisis Asia [Dissertation]. University of California, California (US).

- Kapetanios, et.al, 2000. "Cointegrating VAR Models with Endogenous I(0) Variables: Theoretical Extensions and An Application to UK Monetary Policy." NIESR Discussion Paper, 169.

- Kearns and Manners, 2005. "The Impact Of Monetary Policy On The Exchange Rate: A Study Using Intraday Data Research Discussion Paper.” Economic Research Department (Reserve Bank of Australia). 2, p. 1-24.

- Lutkepohl, Kratzig, 2004. Applied time series econometrics. Cambridge University Press, Cambridge (GB).

- Moentjak, 2014. Central Banking: Theory and Practice in Sustaining Monetary and Financial Stability. Wiley Publisher, New Jersey.

- Mohanty and Klau, 2006. "Monetary Policy Rules in Emerging Market Economies: Issues and Evidence." BIS Working Papers, 149, p. 1-17.

- Mohanty and Berger, 2013. "Central bank views on foreign exchange intervention". BIS Working Paper. 73, p. 55-74.

- Park, 2011. The Essays on Effects and Responses on Monetary Policy [dissertation]. University of California, Los Angeles (US).

- Schmidt-Hebbe and Tapia, 2002 "Monetary Policy Implementation and Results in Twenty InflationTargeting Countries." Central Bank of Chile Working Papers No 166.

- Stone, et.al, 2009. The Role of the Exchange Rate in Inflation-Targeting Emerging Economies. Washington: IMF Occasional Paper. 267, p. 3-26

- Syarifuddin, Hidayat and Tarsidin, 2009. "Impact Of Non-Cash Payment Increase on The Economy And Its Implication For Monetary Control In Indonesia." Bulletin Of Monetary Economics And Banking, 11, 369397.

- Taylor, 2001."The Role of the Exchange Rate in Monetary-Policy Rules". American Economic Review. 2, p. 91. 
- Thiessen, 1995. "Uncertainty and the Transmission of Monetary Policy in Canada." Hermes-Glendon Lecture. York University

- Vargas and Rodriguez, 2013. "Foreign exchange intervention in Colombia". Borradores de Economica, vol, p. 757

- White, 1982. "Maximum Likelihood Estimation of Misspecified Models ." Econometrica, 50, p.1-25 